\title{
Association between single nucleotide polymorphism rs9534275 and the risk of coronary artery disease and ischemic stroke

\author{
Liu Miao ${ }^{1}$, Rui-Xing Yin ${ }^{*}$, Shuo Yang ${ }^{1}$, Feng Huang ${ }^{1}$, Wu-Xian Chen ${ }^{1}$ and Xiao-Li Cao ${ }^{2}$
}

\begin{abstract}
Background: The present study was to detect the association of single nucleotide polymorphism (SNP) in the breast susceptibility gene 2 (BRCA2) and the risk of coronary artery disease (CAD) and ischemic stroke (IS).

Methods: Genotypes of the BRCA2 rs9534275 in 1822 unrelated subjects (CAD, 606; IS, 569; and healthy controls, 647) were determined by the polymerase chain reaction and restriction fragment length polymorphism and then confirmed by direct sequencing.

Results: The genotypic and allelic frequencies of rs9534275 were significantly different between the CAD, IS patients and controls ( $P=0.033$ and $P=0.027$; respectively). The GG, GT/GG genotypes and $\mathrm{G}$ allele were associated with an increased risk of CAD and IS (CAD: $P=0.005$ for GG vs. T, $P=0.004$ for GT/GG vs. $\Pi, P=0.005$ for $\mathrm{G}$ vs. T; IS: $P=0.003$ for $\mathrm{GG}$ vs. $T, P=0.005$ for $\mathrm{GT} / \mathrm{GG}$ vs. $T$; $P=0.002$ for $\mathrm{G}$ vs. T). The $\mathrm{GG}$, GT and $\mathrm{GT} / \mathrm{GG}$ genotypes in the CAD, but not in healthy controls and IS patients, were associated with an increased serum total cholesterol (TC) and apolipoprotein B (ApoB) concentration.
\end{abstract}

Conclusions: The present study shows that the G allele carriers of BRCA2 rs9534275 were associated with increased serum TC and ApoB levels in the CAD patients and increased risk of CAD and IS.

Trial registration: Retrospectively registered.

Keywords: Breast susceptibility gene 2, Single nucleotide polymorphism, Lipids, Coronary artery disease, Ischemic stroke

\section{Background}

Both coronary artery disease (CAD) and ischemic stroke (IS) are the major causes of morbidity and death in the developed countries, and are also the leading cause of long-term disability in survivors [1, 2]. Atherogenic dyslipidemia characterized by low levels of high-density lipoprotein cholesterol (HDL-C) and apolipoprotein (Apo) A1, high levels of total cholesterol (TC), triglyceride (TG) and low-density lipoprotein (LDL) particle number is highly associated with increased incidence of the cardiovascular disease [3] and IS [4, 5]. In addition, genetic factors are estimated to account for about $50-80 \%$ of the variation in serum lipid levels [6], and $30-60 \%$ of the incidence of

\footnotetext{
* Correspondence: yinruixing@163.com

'Department of Cardiology, Institute of Cardiovascular Diseases, The First Affiliated Hospital, Guangxi Medical University, 22 Shuangyong Road, Nanning 530021, Guangxi, People's Republic of China

Full list of author information is available at the end of the article
}

CAD and IS [7]. Therefore, single nucleotide polymorphisms (SNPs) in the lipid-related genes may have some associations with serum lipid levels, and the risk of CAD and IS [8].

A few previous GWASes have proved that the breast cancer susceptibility gene 2 (BRCA2; Also knows as: $F A D$; FACD; FAD1; GLM3; BRCC2; FANCD; PNCA2; FANCD1; XRCC11; BROVCA2, Gene ID: 675, HGNC ID: 1101, synonyms: "BRCA1/BRCA2-containing complex, subunit 2", $B R C C 2$, FAD, FAD1, XRCC11, locus type: gene with protein product, chromosomal location: 13q13.1) mutation can cause an increased risk for breast cancer [9]. Women carrying $B R C A$ mutations have metabolic deregulations in their breast tissue that may be precursors to malignant transformation, and also lead to exhibit a reduction of $79 \%$ in metabolite level, while both lipid unsaturation and TG levels increased by $19 \%$. Besides these, women carrying $B R C A 2$ mutations showed an increased lipid unsaturation 
of $21 \%$ and the metabolic changes in women carrying BRCA1 mutations were different from those in women carrying BRCA2 mutations, with a $47 \%$ increase in cholesterol level recorded in those with BRCA2 mutations [10]. The mechanism was supposed to have a connection with lipid metabolism [11]. A previous GWAS on plasma lipid levels has identified the rs9534275 SNP near the BRCA2 as hyperlipidemic locus in European. And, several previous studies have shown that the BRCA2 rs9534275 may have an effect on TC, low-density lipoprotein cholesterol (LDL-C), and serum lipid levels might have ethnic- and/or sex-specificity [12, 13].

To our knowledge, the genetic evidence on the association between $B R C A 2$ variants and atherosclerosis in humans is poor. In a previous study, we have found that the BRCA2 rs9534275 SNP modulated serum TC, LDL$\mathrm{C}$, ApoB concentrations, and the ApoA1/ApoB ratio in the hypercholesterolemic subjects [14], suggesting that the rs9534275 SNP plays an important role in the formation of atherosclerosis. Therefore, the present study aimed to determine whether the BRCA2 rs9534275 SNP is associated with the risk of CAD and IS in the Guangxi Han population.

\section{Methods \\ Subjects}

A total of 606 patients with CAD and 569 patients with IS were recruited from hospitalized patients in the First Affiliated Hospital, Guangxi Medical University. All of the enrolled CAD patients were evaluated by coronary angiography due to suspected CAD or unrelated conditions requiring angiographic evaluation; the coronary angiograms were analyzed by two experienced interventional cardiologists. CAD was defined as significant coronary stenosis $(\geq 50 \%)$ in at least one of the three main coronary arteries or their major branches (branch diameter $\geq 2 \mathrm{~mm}$ ). Subjects with congenital heart disease and type I diabetes mellitus were excluded [15]. All of the enrolled IS patients received a strict neurological examination and brain magnetic resonance imaging. The diagnosis of IS was according to the International Classification of Diseases (9th Revision). Patients with a transient ischemic attack, embolic brain infarction, stroke caused by inflammatory disease, cardio embolic stroke, autoimmune disease, or serious chronic diseases were excluded from this study. Subjects with a past history of CAD were also excluded from the study [16]. A total of 647 healthy controls matched by age, gender, and geographical area were included. The controls were judged to be free of CAD and IS by questionnaires, medical history, and clinical examination. All individuals enrolled were from the Han population in Guangxi, China. A standard questionnaire was used to ascertain general information and medical history from all participants. The study protocol was approved by the Ethics Committee of the First Affiliated Hospital, Guangxi Medical University (No. Lunshen 2009-Guike018; Jan. 7, 2009). Informed consent was obtained from all subjects after receiving a full explanation of the study [17].

\section{Genotyping and biochemical analysis}

All of the biochemical assays and genotyping in CAD and IS patients were performed after hospitalization, and all of the venous blood samples were obtained from the patients and controls after at least $12 \mathrm{~h}$ of fasting. Genomic DNA was isolated from peripheral blood leukocytes using the phenol-chloroform method. Genotyping of the BRCA2 rs9534275 was performed by polymerase chain reaction and restriction fragment length polymorphism (PCRRFLP). PCR amplification was performed using $5^{\prime}$ TCTTGGCCCAGATGCTTACT-3' as the forward and 5' -TACCAACACTACCACCAGCA-3' as reversed primer pair (Sangon, Shanghai, People's Republic of China), respectively. Each $25 \mu \mathrm{L}$ PCR reaction mixture consisted of $2.0 \mu \mathrm{L}$ genomic DNA, $1.0 \mu \mathrm{L}$ each primer $(10 \mu \mathrm{mol} / \mathrm{L}$ ), $12.5 \mu \mathrm{L}$ of $2 \times$ Taq PCR Master mix (constituent: $0.1 \mathrm{U}$ Taq polymerase $/ \mu \mathrm{L}, 500 \mu \mathrm{M}$ dNTP each and PCR buffer.), and $8.5 \mu \mathrm{L}$ of $\mathrm{ddH}_{2} \mathrm{O}$ (DNase/RNasefree). PCR was performed with an initialization step of $95{ }^{\circ} \mathrm{C}$ for $5 \mathrm{~min}$, followed by $30 \mathrm{~s}$ denaturing at $95^{\circ} \mathrm{C}, 30 \mathrm{~s}$ of annealing at $59{ }^{\circ} \mathrm{C}$ and $35 \mathrm{~s}$ of elongation at $72{ }^{\circ} \mathrm{C}$ for 33 cycles. The amplification was completed by a final extension at $72{ }^{\circ} \mathrm{C}$ for $7 \mathrm{~min}$. Following electrophoresis on a $2.0 \%$ agarose gel with $0.5 \mu \mathrm{g} / \mathrm{mL}$ ethidium bromide, the amplification products were visualized under ultraviolet light. Subsequently, each restriction enzyme reaction was performed with $5.0 \mu \mathrm{L}$ amplified DNA, $8.8 \mu \mathrm{L}$ nucleasefree water, $1.0 \mu \mathrm{L}$ of $10 \times$ buffer solution and $0.2 \mu \mathrm{L} R s a \mathrm{I}$ restriction enzyme in a total volume of $15 \mu \mathrm{L}$ digested at $37{ }^{\circ} \mathrm{C}$ overnight. After restriction enzyme digestion of the amplified DNA, genotypes were identified by electrophoresis on $2 \%$ ethidium-bromide stained agarose gels and visualized with UV illumination. An experienced reader blinded to the epidemiological and serum lipid results scored the genotypes. Six samples (TT, GT and GG genotypes in two (Figs. 1, 2 and 3; respectively) detected by the PCR-RFLP were also confirmed by direct sequencing with an ABI Prism 3100 (Applied Biosystems) in Shanghai Sangon Biological Engineering Technology \& Services Co., Ltd., People's Republic of China [18]. The levels of serum TC, TG, HDL-C, and LDL-C in the samples were determined by enzymatic methods with commercially available kits. Serum ApoA1 and ApoB levels were detected by an immunoturbidimetric immunoassay using a commercial kit $[19,20]$.

\section{Diagnostic criteria}

The normal values of serum TC, TG, HDL-C, LDL-C, ApoA1, ApoB levels and the ApoA1/ApoB ratio in our 


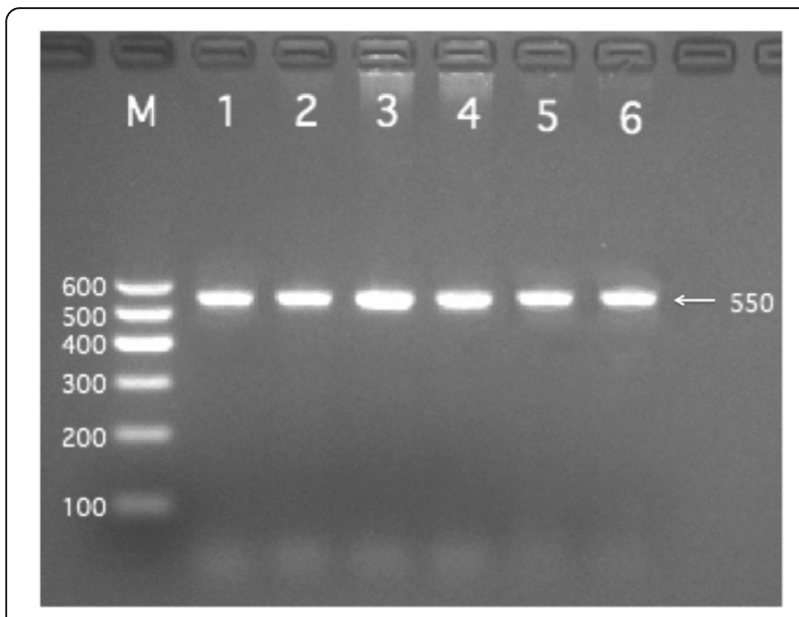

Fig. 1 Electrophoresis of polymerase chain reaction products of the samples. Lane $\mathrm{M}$ is the $100 \mathrm{bp}$ marker ladder; Lanes 1-6 are samples, the $550 \mathrm{bp}$ bands are the target genes

Clinical Science Experiment Center were 3.10-5.17, $0.56-1.70, \quad 0.91-1.81, \quad 2.70-3.20 \mathrm{mmol} / \mathrm{L}, \quad 1.00-1.78$, $0.63-1.14 \mathrm{~g} / \mathrm{L}$, and 1.00-2.50; respectively. The individuals with $\mathrm{TC}>5.17 \mathrm{mmol} / \mathrm{L}$ and/or TG $>1.70 \mathrm{mmol} / \mathrm{L}$ were defined as hyperlipidemic. Hypertension was diagnosed according to the criteria from the 1999 World Health Organization-International Society of Hypertension Guidelines for the management of hypertension [21]. The diagnostic criteria of overweight and obesity were according to the Cooperative Meta-analysis Group of China Obesity Task Force. Normal weight, overweight and obesity were defined as a BMI $<24,24-28$ and $>28 \mathrm{~kg} / \mathrm{m}^{2}$, respectively [22]. Dyslipidemia was defined according to World Health Organization criteria: TG $\geq 1.7 \mathrm{mmol} / \mathrm{L}$ and HDL-C $<0.9 \mathrm{mmol} / \mathrm{L}$ for men or $<1.0 \mathrm{mmol} / \mathrm{L}$ for women. Diabetes was defined as a fasting plasma glucose

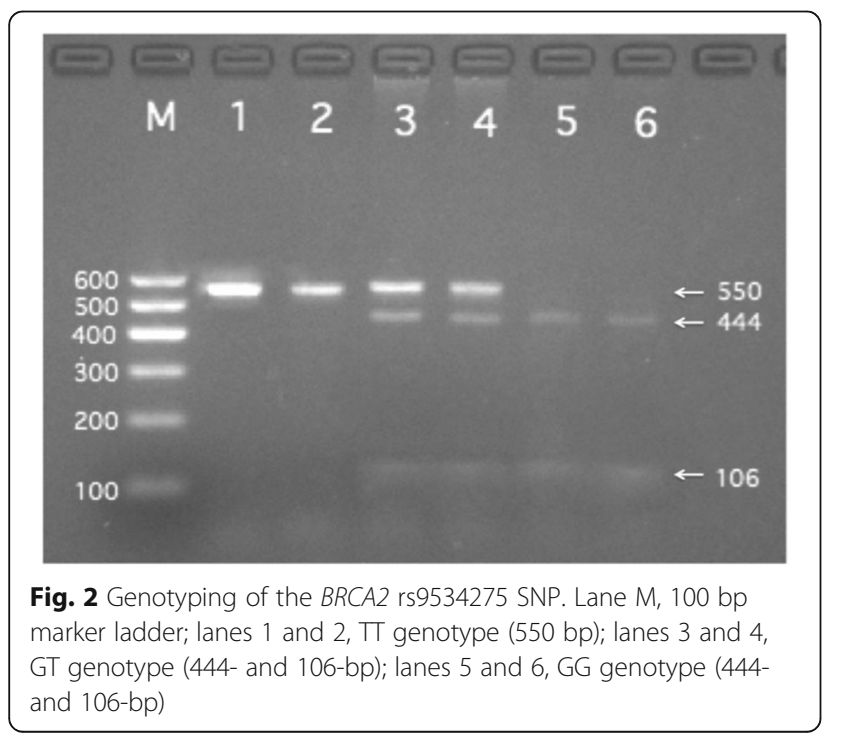

$\geq 7.0 \mathrm{mmol} / \mathrm{L}$ or $2 \mathrm{~h}$ postprandial plasma glucose $\geq 11.1 \mathrm{mmol} / \mathrm{L}$ or as having been previously diagnosed with diabetes and receiving therapy [23].

\section{Statistical analyses}

All statistical analyses were performed using the statistical software package SPSS 21.0 (SPSS Inc. Chicago, IL, USA). A standard goodness-of-fit test was used to test the HardyWeinberg equilibrium. A chi-square analysis was used to evaluate the difference in genotype distribution and sex ratio between the groups. The general characteristics between the cases and controls were tested using Student's unpaired $t$-test. The association between genotypes and serum lipid parameters was tested by analysis of covariance (ANCOVA). Sex, age, body mass index (BMI), blood pressure, alcohol consumption, and cigarette smoking were adjusted for the statistical analysis. Odds ratio (OR) and 95\% confidence interval (CI) were calculated using unconditional logistic regression. A two-tailed $P$ value less than 0.05 was considered to be statistically significant.

\section{Results}

\section{General characteristics and serum lipid levels}

The baseline characteristics of the patients with CAD or IS and the controls are shown in Table 1. The mean age, male to female ratio, average BMI, serum TG, ApoA1, ApoB levels and the ApoA1/ApoB ratio and the percentages of subjects who smoked cigarettes were similar between the controls and CAD patients or between the controls and IS patients. The average height, weight, systolic blood pressure, pulse pressure, glucose, serum TC and LDL-C levels were significantly higher and serum HDL-C and the percentages of subjects who consumed alcohol were significantly lower in the CAD and IS patients than in the controls. The average diastolic blood pressure was lower in CAD patients, but higher in IS patients as compared with controls.

\section{Genotypic and allelic frequencies}

The frequency of the $\mathrm{T}$ and $\mathrm{G}$ alleles was $55.3 \%$ and $44.7 \%$ in the controls, $50.8 \%$ and $49.2 \%$ in the CAD patients $(P=0.025)$, and $50.2 \%$ and $49.8 \%$ in the IS patients $(P=0.012)$, respectively (Table 2$)$. The frequency of the TT, GT and GG genotypes was $31.4 \%$, $47.9 \%$ and $20.7 \%$ in the controls, $24.8 \%, 52.1 \%$ and $23.1 \%$ in the CAD patients $(P=0.033)$, and $24.6 \%, 51.1 \%$ and $24.3 \%$ in the IS patients $(P=0.027)$, respectively. The genotypic and allelic frequencies were concordant with those predicted by the Hardy-Weinberg proportions in both experimental groups $(P=0.330$ for CAD and $P=0.620$ for IS $)$ and controls $(P=0.349)$. 


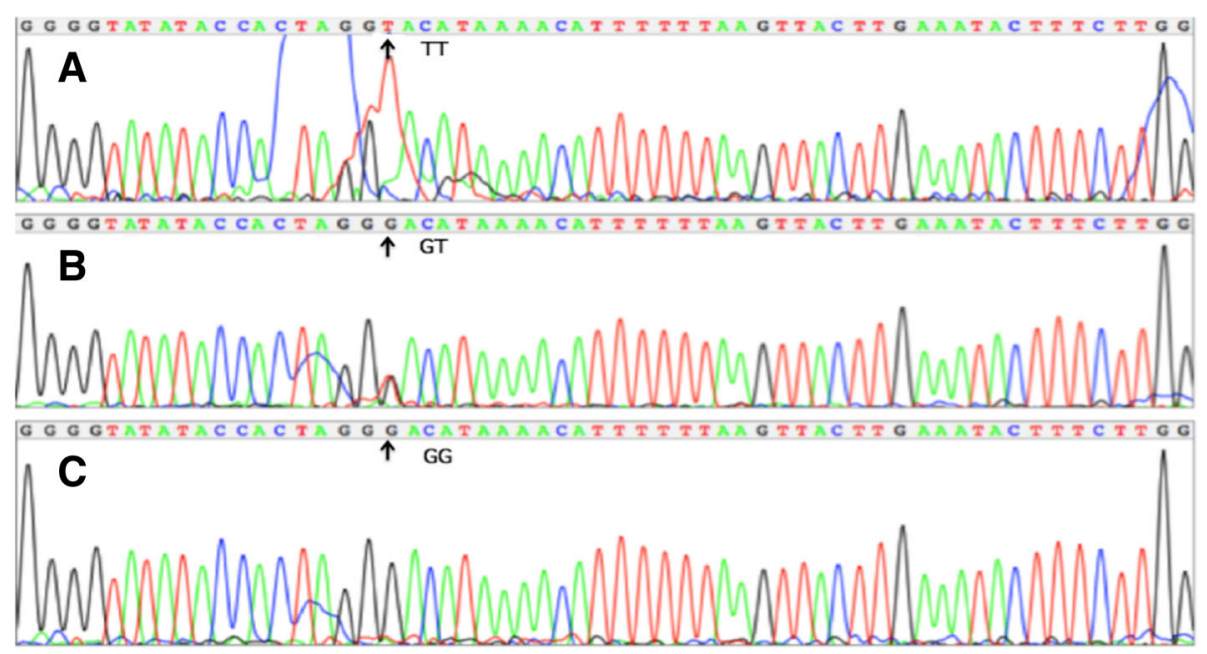

Fig. 3 A part of the nucleotide sequence of the BRCA2 rs9534275 SNP. a: TT genotype; b: GT genotype; and c: GG genotype

BRCA2 rs9534275 SNP and the risk of CAD and IS

The $\mathrm{G}$ allele was associated with an increased risk of $\mathrm{CAD}$ (adjusted $\mathrm{OR}=1.35,95 \% \mathrm{CI}=1.14-1.60$ ) and $\mathrm{IS}$ (adjusted OR $=1.37,95 \% \mathrm{CI}=1.16-1.62$; Table 2). The GG and GT/GG genotypes were also associated with an increased risk of CAD (adjusted OR $=1.78,95 \% \mathrm{CI}=0.82$ 1.91 for GG vs. TT and adjusted OR $=1.63,95 \% \mathrm{CI}=1.25-$
2.12 for GT/GG vs. TT) and IS (adjusted OR $=1.85$, 95\% CI $=1.32-2.59$ for $\mathrm{GG}$ vs. $\mathrm{TT}$ and adjusted $\mathrm{OR}=1.61,95 \% \mathrm{CI}=1.24-2.10$ for $\mathrm{GT} / \mathrm{GG}$ vs. $\mathrm{TT})$. Stratified analysis showed an increased risk of CAD in subjects with a GT/GG genotype, mainly in those who were part of one of the following groups: high BMI (adjusted $\mathrm{OR}=1.47,95 \% \mathrm{CI}=0.98-2.20$ ), smokers (adjusted

Table 1 Comparison of demographic, lifestyle characteristics and serum lipid levels of the participants

\begin{tabular}{|c|c|c|c|c|c|}
\hline \multirow[t]{2}{*}{ Characteristic } & \multirow{2}{*}{$\begin{array}{l}\text { Control } \\
(n=647)\end{array}$} & \multicolumn{2}{|l|}{ Case } & \multicolumn{2}{|c|}{$P_{\text {vs.controls }}$} \\
\hline & & $\mathrm{CAD}(n=606)$ & IS $(n=569)$ & $C A D$ & is \\
\hline Male/female & $475 / 172$ & $447 / 159$ & $410 / 159$ & 0.898 & 0.606 \\
\hline Age (years) & $61.71 \pm 9.60$ & $62.21 \pm 10.54$ & $62.85 \pm 12.33$ & 0.596 & 0.451 \\
\hline Height (cm) & $155.09 \pm 7.82$ & $164.10 \pm 6.91$ & $163.73 \pm 7.27$ & 0.026 & 0.042 \\
\hline Weight (kg) & $54.55 \pm 9.00$ & $64.62 \pm 10.63$ & $63.08 \pm 11.06$ & 0.000 & 0.000 \\
\hline BMI $\left(\mathrm{kg} / \mathrm{m}^{2}\right)$ & $22.66 \pm 3.19$ & $23.93 \pm 3.22$ & $23.47 \pm 3.49$ & 0.640 & 0.531 \\
\hline $\mathrm{SBP}(\mathrm{mmHg})$ & $127.53 \pm 18.71$ & $132.89 \pm 23.37$ & $147.24 \pm 22.30$ & 0.000 & 0.000 \\
\hline $\mathrm{DBP}(\mathrm{mmHg})$ & $80.29 \pm 11.30$ & $79.19 \pm 13.24$ & $83.62 \pm 12.81$ & 0.023 & 0.002 \\
\hline $\mathrm{PP}(\mathrm{mmHg})$ & $47.23 \pm 13.69$ & $53.69 \pm 17.18$ & $63.63 \pm 18.08$ & 0.000 & 0.000 \\
\hline Smoking, n (\%) & 257(39.7) & $272(44.9)$ & 247(43.4) & 0.067 & 0.200 \\
\hline Alcohol, n (\%) & 279(43.1) & 155(25.6) & $168(29.5)$ & 0.000 & 0.000 \\
\hline Glu (mmol/L) & $6.18 \pm 1.76$ & $6.38 \pm 1.41$ & $6.41 \pm 1.52$ & 0.004 & 0.000 \\
\hline TC (mmol/L) & $4.50 \pm 0.57$ & $4.55 \pm 1.20$ & $4.53 \pm 1.15$ & 0.000 & 0.000 \\
\hline TG $(\mathrm{mmol} / \mathrm{L})$ & $1.42 \pm 1.74$ & $1.67 \pm 1.09$ & $1.71 \pm 1.53$ & 0.747 & 0.277 \\
\hline $\mathrm{HDL}-\mathrm{C}(\mathrm{mmol} / \mathrm{L})$ & $1.90 \pm 0.48$ & $1.15 \pm 0.33$ & $1.23 \pm 0.40$ & 0.000 & 0.000 \\
\hline LDL-C (mmol/L) & $2.75 \pm 0.72$ & $2.96 \pm 0.96$ & $2.93 \pm 0.84$ & 0.000 & 0.000 \\
\hline Apo A1, g/L & $1.41 \pm 0.27$ & $1.04 \pm 0.53$ & $1.02 \pm 0.22$ & 0.229 & 0.069 \\
\hline ApoB, g/L & $0.91 \pm 0.20$ & $1.10 \pm 4.56$ & $0.99 \pm 0.24$ & 0.101 & 0.203 \\
\hline ApoA1/ApoB & $1.64 \pm 0.51$ & $1.21 \pm 0.50$ & $1.09 \pm 0.37$ & 0.113 & 0.216 \\
\hline
\end{tabular}

$S B P$, Systolic blood pressure; DBP, Diastolic blood pressure; $P P$, Pulse pressure; Glu, Glucose; HDL-C, high-density lipoprotein cholesterol; $L D L-C$, low-density lipoprotein cholesterol; $A$ po, Apolipoprotein. $T C$, Total cholesterol; $T G$, Triglyceride; The value of triglyceride was presented as median (interquartile range), the difference between the control and CAD/IS groups was determined by the Wilcoxon-Mann-Whitney test 
Table 2 Genotype and allele frequencies of the BRCA2 rs9534275 SNP in cases and controls

\begin{tabular}{|c|c|c|c|c|c|c|c|}
\hline \multirow{2}{*}{$\begin{array}{l}\text { Genotype } \\
\text { or allele }\end{array}$} & \multirow{2}{*}{$\begin{array}{l}\text { Control } \\
{[n(\%)]}\end{array}$} & \multirow{2}{*}{$\begin{array}{l}\text { CAD } \\
{[n(\%)]}\end{array}$} & \multirow{2}{*}{$\begin{array}{l}\text { IS } \\
{[n(\%)]}\end{array}$} & \multicolumn{2}{|l|}{ CAD } & \multicolumn{2}{|l|}{ IS } \\
\hline & & & & OR $(95 \% \mathrm{Cl})$ & P & OR $(95 \% \mathrm{Cl})$ & $P$ \\
\hline$\pi$ & $203(31.4)$ & $150(24.8)$ & $140(24.6)$ & 1 & & 1 & \\
\hline GT & $310(47.9)$ & $316(52.1)$ & 291 (51.1) & $1.58(1.19-2.08)$ & 0.365 & $1.52(1.15-2.01)$ & 0.214 \\
\hline GG & $134(20.7)$ & $140(23.1)$ & $138(24.3)$ & $1.78(0.82-1.91)$ & 0.005 & $1.85(1.32-2.59)$ & 0.003 \\
\hline$x^{2}$ & & 6.812 & 7.257 & & & & \\
\hline$P$ & & 0.033 & 0.027 & & & & \\
\hline HWE $(P)$ & 0.349 & 0.33 & 0.62 & & & & \\
\hline$\pi$ & $203(31.4)$ & $150(24.8)$ & $140(24.6)$ & 1 & & 1 & \\
\hline GT/GG & $444(68.6)$ & $456(75.2)$ & $429(75.4)$ & $1.63(1.25-2.12)$ & 0.004 & $1.61(1.24-2.10)$ & 0.005 \\
\hline$x^{2}$ & & 6.783 & 6.854 & & & & \\
\hline$P$ & & 0.01 & 0.009 & & & & \\
\hline T & 716 (55.3) & $616(50.8)$ & $571(50.2)$ & 1 & & 1 & \\
\hline G & $578(44.7)$ & $596(49.2)$ & $567(49.8)$ & $1.35(1.14-1.60)$ & 0.005 & $1.37(1.16-1.62)$ & 0.002 \\
\hline$x^{2}$ & & 5.106 & 6.462 & & & & \\
\hline$P$ & & 0.025 & 0.012 & & & & \\
\hline
\end{tabular}

Adjusted for sex, age, smoking, drinking, BMI, diabetes, hypertension, hyperlipidemia. CAD, coronary artery disease; IS, ischemic stroke

$\mathrm{OR}=1.48,95 \% \mathrm{CI}=1.03-2.14)$. There was an increased risk of IS in subjects with a GT/GG genotype, mainly in those who belonged to one of the following groups: high BMI (adjusted OR $=1.49,95 \% \mathrm{CI}=0.97-2.23$ ), smokers (adjusted OR $=1.90,95 \% \mathrm{CI}=1.29-2.80$ ) (Table 3). No significant interaction was detected between the genotypes and these factors.

\section{Related risk factors for CAD and IS}

Multivariate logistic analysis showed that the incidence of CAD and IS positively correlated with smoking, BMI and rs9534275 GT/GG genotypes and negatively correlated with the alcohol consumption. In the meantime, the hyperlipidemia was positively correlated with CAD and hypertension was also positively correlated with IS (Table 4).

\section{Genotypes and serum lipid levels}

As shown in Table 5, the TC and ApoB levels in the CAD patients were different among the TT, GT and GG genotypes $(P=0.023$ and $P=0.043$; respectively), the $G$ allele carriers had higher TC and ApoB levels than the $\mathrm{G}$ allele non-carriers $(P=0.018$ and $P=0.031$; respectively).

\section{Discussion}

With the remarkable improvement of social living standard, the development of CAD was influenced by both genetic and environmental factors, as evident by its high heritability (40-50\%), shown in twin and family studies [24]. Hypertension [25], obesity [26], abdominal fat [27], diabetes [28], dyslipidemia [29-31], inflammation as reflected by high levels of C-reactive protein (CRP) [32], are associated with CAD. The present study shows that the genotypic and allelic frequencies of the rs9534275 SNP were significantly different between the patients with CAD or IS and controls, and the GG, GT/GG genotypes and G allele were associated with an increased risk of CAD and IS. That was to say, the rs9534275 SNP would be a genetic factor contribute to CAD and IS.

In a previous association study, the $B R C A$ mutations were found in about $20 \%$ of all hereditary breast cancers and women carrying $B R C A 1$ and $B R C A 2$ mutation were easily caught up with breast cancer [33]. Hsu et al. had found that lipids are recognized to play a crucial role in tumor development and progression, especially in breast cancer [34]. It has been showed that hypercholesterolemia increased the enzymatic formation of the oxysterol 27$\mathrm{OHC}$ and accelerated tumor formation and progression in murine breast cancer models [35]. Hypercholesterolemia, not only could it cause cancer, but also it can lead to atherosclerosis which the common pathophysiologic mechanisms of CAD and IS [36]. In the current study, we found that the $G$ allele carriers had higher $\mathrm{TC}$ and ApoB levels in $\mathrm{CAD}$, that would be another promising aspect to increase the risk of CAD for BRCA2 rs9534275 SNP.

As taken several environment exposures into consideration, an increased risk of CAD and IS in subjects with a GT/GG genotype was mainly noted in those with high BMI or smokers. Bangalore et al. found that fluctuation in body weight was associated with higher mortality and a higher rate of cardiovascular events independent of traditional cardiovascular risk factors [37]. Several studies have demonstrated that obesity is a common risk factor for several subtypes of cardiovascular disease, including CAD, stroke, and heart failure [38-41]. Besides, some 
Table 3 The risk of rs9534275 for CAD and IS according to body mass index (BMI), gender, smoking and drinking

\begin{tabular}{|c|c|c|c|c|c|c|c|}
\hline \multirow[t]{2}{*}{ Factors } & \multirow[t]{2}{*}{ Genetype } & \multicolumn{3}{|l|}{ CAD } & \multicolumn{3}{|l|}{ IS } \\
\hline & & OR $(95 \% \mathrm{Cl})$ & $P$ & $P_{\text {interaction }}$ & OR $(95 \% \mathrm{Cl})$ & $P$ & $P_{\text {interaction }}$ \\
\hline \multicolumn{8}{|l|}{ BMl } \\
\hline \multirow[t]{2}{*}{$<24 \mathrm{Kg} / \mathrm{m}^{2}$} & TT GT/GG & 1 & & 0.480 & 1 & & 0.560 \\
\hline & & $1.34(0.97-1.87)$ & 0.078 & & $1.36(0.97-1.87)$ & 0.061 & \\
\hline \multirow[t]{2}{*}{$\geq 24 \mathrm{Kg} / \mathrm{m}^{2}$} & $\pi$ & 1 & & & 1 & & \\
\hline & GT/GG & $1.47(0.98-2.20)$ & 0.034 & & $1.49(0.97-2.23)$ & 0.047 & \\
\hline \multicolumn{8}{|l|}{ Gender } \\
\hline \multirow[t]{2}{*}{ Male } & $\Pi \mathrm{TT} / \mathrm{GG}$ & 1 & & 0.053 & 1 & & 0.068 \\
\hline & & $0.90(0.61-1.23)$ & 0.681 & & $0.97(0.73-1.34)$ & 0.924 & \\
\hline \multirow[t]{2}{*}{ Female } & $\pi$ & 1 & & & 1 & & \\
\hline & GT/GG & $4.20(2.56-4.69)$ & 0.072 & & $3.22(2.01-5.22)$ & 0.064 & \\
\hline \multicolumn{8}{|l|}{ Smoking } \\
\hline \multirow[t]{2}{*}{ Nonsmoker } & $\pi$ & 1 & & 0.350 & 1 & & 0.160 \\
\hline & GT/GG & $1.38(0.98-1.94)$ & 0.068 & & $1.13(0.80-1.57)$ & 0.492 & \\
\hline \multirow[t]{2}{*}{ Smoker } & $\pi$ & 1 & & & 1 & & \\
\hline & GT/GG & $1.48(1.03-2.14)$ & 0.034 & & $1.90(1.29-2.80)$ & 0.001 & \\
\hline \multicolumn{8}{|l|}{ Drinking } \\
\hline \multirow[t]{2}{*}{ Nondrinker } & $\pi$ & 1 & & 0.520 & 1 & & 0.093 \\
\hline & GT/GG & $0.73(0.64-1.12)$ & 0.335 & & $0.87(0.68-3.73)$ & 0.565 & \\
\hline \multirow[t]{2}{*}{ Drinker } & $\pi$ & 1 & & & 1 & & \\
\hline & GT/GG & $0.81(0.66-1.28)$ & 0.223 & & $0.94(0.71-3.92)$ & 0.324 & \\
\hline
\end{tabular}

$C A D$, coronary artery disease; $I S$, ischemic stroke

Table 4 The relative risk factors for CAD and IS

\begin{tabular}{|c|c|c|c|c|}
\hline \multirow[t]{2}{*}{ Relatives factors } & \multicolumn{2}{|l|}{ CAD } & \multicolumn{2}{|l|}{ IS } \\
\hline & OR $(95 \% \mathrm{Cl})$ & $P$ & OR $(95 \% \mathrm{Cl})$ & $P$ \\
\hline Nonsmoking & 1 & & 1 & \\
\hline Smoking & $1.92(1.45-2.51)$ & 0.013 & $1.80(1.36-2.39)$ & 0.022 \\
\hline Nondrinking & 1 & & 1 & \\
\hline Drinking & $0.29(0.22-0.38)$ & 0.006 & $0.34(0.26-0.41)$ & 0.010 \\
\hline $\mathrm{BMI}<24 \mathrm{Kg} / \mathrm{m}^{2}$ & 1 & & 1 & \\
\hline $\mathrm{BMI} \geq 24 \mathrm{Kg} / \mathrm{m}^{2}$ & $2.07(1.62-2.65)$ & 0.018 & $1.47(1.14-1.90)$ & 0.031 \\
\hline Rs9534275 Tा & 1 & & 1 & \\
\hline Rs9534275 GT/GG & $1.47(1.13-1.92)$ & 0.004 & $1.46(1.12-1.90)$ & 0.005 \\
\hline Non-diabetes & 1 & & 1 & \\
\hline Diabetes & $1.08(0.81-1.45)$ & 0.466 & $1.28(0.96-1.70)$ & 0.092 \\
\hline Normotensive & 1 & & 1 & \\
\hline Hypertension & $1.11(0.84-1.45)$ & 0.608 & $1.55(1.19-2.02)$ & 0.010 \\
\hline Normal blood lipids & 1 & & 1 & \\
\hline Hyperlipidemia & $2.48(1.87-3.29)$ & 0.004 & $2.18(1.64-2.90)$ & 0.008 \\
\hline
\end{tabular}

$C A D$, coronary artery disease; $I S$, ischemic stroke previous researches found that smoking altered serum lipid profiles, as characterized by increased TC, TG, LDL-C levels and the ApoB/ApoA1 ratio, along with decreased HDL-C levels. These changes would regulate the risk of CAD and IS [42-44]. In our present study, the interaction between BRCA2 rs9534275 SNP and high BMI or smoking, and an increased risk of $C A D$ and IS were also discovered.

Nowadays, the clinical beneficial effects of therapy in reducing the risk of coronary events and mortality in patients with CAD or IS are believed to be the result of its cholesterol-lowering actions [45], the quest for pharmacologic agents that target in treating atherogenesis has intensified in recent years. In the present study, we showed that the BRCA2 rs9534275 SNP not only modified serum lipid levels and the risk of CAD and IS, but also interacted with environment exposures. Thus, the BRCA2 rs9534275 SNP may be a promising drug target for therapeutic intervention against hyperlipidemia and atherosclerosis.

There are several potential limitations in the present study. Firstly, many patients were taking medications such as lipid-lowering drugs (statins or fibrates), ACE inhibitors, beta blockers, diuretics, aspirin, and anti-atherosclerotic drugs. All of these drugs have different effects on serum lipid levels. Secondly, the mean values of height, weight, $\mathrm{BMI}$ and blood pressure were higher and the percentage of 
Table 5 Association of the genotypes and serum lipid levels in controls and CAD and IS patients

\begin{tabular}{|c|c|c|c|c|c|c|c|c|}
\hline Genotype & $n$ & $\mathrm{TC}(\mathrm{mmol} / \mathrm{L})$ & $\mathrm{TG}(\mathrm{mmol} / \mathrm{L})$ & $\mathrm{HDL}-\mathrm{C}(\mathrm{mmol} / \mathrm{L})$ & $\mathrm{LDL}-\mathrm{C}(\mathrm{mmol} / \mathrm{L})$ & ApoA1 (g/L) & ApoB (g/L) & ApoA1/ApoB \\
\hline \multicolumn{9}{|l|}{ Control } \\
\hline$\pi$ & 203 & $4.58 \pm 0.71$ & $1.53 \pm 2.38$ & $1.90 \pm 0.52$ & $2.80 \pm 0.75$ & $1.43 \pm 0.31$ & $0.91 \pm 0.22$ & $1.65 \pm 0.54$ \\
\hline GT & 310 & $4.46 \pm 0.50$ & $1.37 \pm 1.18$ & $1.85 \pm 0.42$ & $2.74 \pm 0.70$ & $1.40 \pm 0.23$ & $0.90 \pm 0.19$ & $1.64 \pm 0.51$ \\
\hline GG & 134 & $4.48 \pm 0.49$ & $1.38 \pm 1.70$ & $1.98 \pm 0.54$ & $2.72 \pm 0.62$ & $1.42 \pm 0.27$ & $0.91 \pm 0.26$ & $1.64 \pm 0.46$ \\
\hline$P$ & & 0.070 & 0.580 & 0.058 & 0.530 & 0.444 & 0.629 & 0.941 \\
\hline$\pi$ & 203 & $4.58 \pm 0.71$ & $1.53 \pm 2.38$ & $1.90 \pm 0.52$ & $2.80 \pm 0.75$ & $1.43 \pm 0.31$ & $0.91 \pm 0.22$ & $1.65 \pm 0.54$ \\
\hline $\mathrm{GT}+\mathrm{GG}$ & 444 & $4.62 \pm 0.49$ & $1.47 \pm 1.36$ & $1.89 \pm 0.46$ & $2.75 \pm 0.99$ & $1.40 \pm 0.25$ & $0.92 \pm 0.26$ & $1.63 \pm 0.49$ \\
\hline P & & 0.072 & 0.297 & 0.786 & 0.278 & 0.283 & 0.374 & 0.729 \\
\hline \multicolumn{9}{|l|}{ CAD } \\
\hline$\pi$ & 150 & $4.55 \pm 1.41$ & $1.66 \pm 1.09$ & $1.13 \pm 0.30$ & $2.88 \pm 0.75$ & $1.07 \pm 0.86$ & $0.90 \pm 0.27$ & $1.23 \pm 0.48$ \\
\hline GT & 316 & $4.58 \pm 2.78$ & $1.70 \pm 1.11$ & $1.16 \pm 0.34$ & $2.92 \pm 1.02$ & $1.04 \pm 0.38$ & $1.63 \pm 9.16$ & $1.21 \pm 0.52$ \\
\hline GG & 140 & $4.61 \pm 3.61$ & $1.64 \pm 1.03$ & $1.16 \pm 0.36$ & $3.01 \pm 1.33$ & $1.03 \pm 0.34$ & $1.54 \pm 4.43$ & $1.17 \pm 0.50$ \\
\hline$P$ & & 0.023 & 0.834 & 0.652 & 0.710 & 0.738 & 0.043 & 0.565 \\
\hline$\pi$ & 150 & $4.55 \pm 1.41$ & $1.66 \pm 1.09$ & $1.13 \pm 0.30$ & $2.88 \pm 0.75$ & $1.07 \pm 0.86$ & $0.90 \pm 0.27$ & $1.23 \pm 0.48$ \\
\hline $\mathrm{GT}+\mathrm{GG}$ & 456 & $4.72 \pm 6.38$ & $1.78 \pm 1.39$ & $1.15 \pm 0.34$ & $2.95 \pm 0.99$ & $1.04 \pm 0.37$ & $1.62 \pm 5.52$ & $1.20 \pm 0.51$ \\
\hline$P$ & & 0.018 & 0.810 & 0.356 & 0.887 & 0.443 & 0.031 & 0.548 \\
\hline \multicolumn{9}{|l|}{ IS } \\
\hline$\pi$ & 140 & $4.60 \pm 1.46$ & $1.90 \pm 2.23$ & $1.26 \pm 0.54$ & $2.90 \pm 0.87$ & $1.02 \pm 0.24$ & $0.99 \pm 0.22$ & $1.12 \pm 0.56$ \\
\hline GT & 291 & $4.52 \pm 1.02$ & $1.66 \pm 1.22$ & $1.21 \pm 0.35$ & $2.94 \pm 0.83$ & $1.03 \pm 0.33$ & $1.06 \pm 0.19$ & $1.09 \pm 0.51$ \\
\hline GG & 138 & $4.52 \pm 1.07$ & $1.62 \pm 1.21$ & $1.24 \pm 0.33$ & $2.93 \pm 0.84$ & $1.05 \pm 0.22$ & $1.03 \pm 0.26$ & $1.09 \pm 0.46$ \\
\hline P & & 0.777 & 0.232 & 0.456 & 0.930 & 0.896 & 0.789 & 0.713 \\
\hline$\pi$ & 140 & $4.60 \pm 1.46$ & $1.90 \pm 2.23$ & $1.26 \pm 0.54$ & $2.90 \pm 0.87$ & $1.02 \pm 0.24$ & $0.99 \pm 0.22$ & $1.12 \pm 0.56$ \\
\hline $\mathrm{GT}+\mathrm{GG}$ & 337 & $4.58 \pm 1.38$ & $1.65 \pm 1.39$ & $1.22 \pm 0.48$ & $2.94 \pm 0.99$ & $1.06 \pm 0.62$ & $1.04 \pm 0.26$ & $1.09 \pm 0.51$ \\
\hline$P$ & & 0.478 & 0.090 & 0.278 & 0.705 & 0.971 & 0.702 & 0.412 \\
\hline
\end{tabular}

Adjusted for sex, age, smoking, drinking, BMI, diabetes, hypertension, hyperlipidemia. $T C$, total cholesterol; $T G$, triglyceride; $H D L-C$, high-density lipoprotein cholesterol; $L D L-C$, low-density lipoprotein cholesterol; $A p 0 A 1$, apolipoprotein $A 1 ; A p o B$, apolipoprotein $B$

subjects who consumed alcohol was lower in CAD/IS patients than in controls. Although some factors such as sex, age, BMI, blood pressure, alcohol consumption, and cigarette smoking have been adjusted for the statistical analysis, the influence of these factors on serum lipid levels was not excluded completely. Finally although we found that the rs9534275 G allele was associated with an increased concentration of serum TC and ApoB, and also the risk of CAD and IS, we did not clarify the mechanism so that more experiments should be carried out.

\section{Conclusions}

The present study shows that the genotypic and allelic frequencies of the rs9534275 SNP were significantly different between the patients with CAD or IS and controls. Subjects with GG genotype or G allele were associated with an increased risk of CAD and IS in smokers and subjects with a BMI $\geq 24 \mathrm{~kg} / \mathrm{m}^{2}$. The GT/GG genotypes were also associated with increased serum TC and ApoB in CAD. These results suggest that the rs9534275 $\mathrm{G}$ allele was associated with increased serum TC and $\mathrm{ApoB}$ in $\mathrm{CAD}$ and with an increased risk of CAD and IS.

\section{Abbreviations}

ANCOVA: Analysis of covariance; Apo: Apolipoprotein; BMl: Body mass index; GWAS: Genome-wide association study; HDL-C: High-density lipoprotein cholesterol; HWE: Hardy-Weinberg equilibrium; LDL-C: Low-density lipoprotein cholesterol; PCR: Polymerase chain reaction; RFLP: Restriction fragment length polymorphism; SNP: Single nucleotide polymorphism; TC: Total cholesterol;

TG: Triglyceride

\section{Acknowledgements}

Not applicable.

\section{Funding}

This study was supported by the National Natural Science Foundation of China (No: 81160111)

\section{Availability of data and materials}

The datasets generated during the present study are not publicly available, because detailed genetic information of each participant were included in these materials.

\section{Authors' contributions}

LM conceived the study, participated in the design, undertook genotyping, performed the statistical analyses, and drafted the manuscript. RXY conceived the study, participated in the design, carried out the epidemiological survey, 
collected the samples, and helped to draft the manuscript. SY collaborated to the genotyping. FH, WXC and XLC carried out the epidemiological survey, and collected the samples. All authors read and approved the final manuscript.

\section{Ethics approval and consent to participate}

The study design was approved by the Ethics Committee of the First Affiliated Hospital, Guangxi Medical University (No. Lunshen 2009-Guike-018; Jan. 7, 2009). Informed consent was obtained from all participants.

\section{Consent for publication}

Informed consent including consent to publish was obtained from all participants by signature or by fingerprint (to express consent), as approved by the ethical review committee.

\section{Competing interests}

The authors declare that they have no competing interests.

\section{Publisher's Note}

Springer Nature remains neutral with regard to jurisdictional claims in published maps and institutional affiliations.

\begin{abstract}
Author details
${ }^{1}$ Department of Cardiology, Institute of Cardiovascular Diseases, The First Affiliated Hospital, Guangxi Medical University, 22 Shuangyong Road, Nanning 530021, Guangxi, People's Republic of China. ${ }^{2}$ Department of Neurology, The First Affiliated Hospital, Guangxi Medical University, 22 Shuangyong Road, Nanning 530021, Guangxi, People's Republic of China.
\end{abstract}

Received: 18 July 2017 Accepted: 26 September 2017 Published online: 05 October 2017

\section{References}

1. WHO publishes definitive atlas on global heart disease and stroke epidemic. Indian J Med Sci 2004, 58:405-406.

2. Bake S, Selvamani A, Cherry J, Sohrabji F. Blood brain barrier and neuroinflammation are critical targets of IGF-1-mediated neuroprotection in stroke for middle-aged female rats. PLoS One. 2014;9:e91427.

3. Bosomworth NJ. Approach to identifying and managing atherogenic dyslipidemia: a metabolic consequence of obesity and diabetes. Can Fam Physician. 2013;59:1169-80.

4. Tanne D, Yaari S, Goldbourt U. High-density lipoprotein cholesterol and risk of ischemic stroke mortality. A 21-year follow-up of 8586 men from the Israeli Ischemic Heart Disease Study. Stroke. 1997:28:83-7.

5. Soyama Y, Miura K, Morikawa Y, Nishijo M, Nakanishi Y, Naruse Y, Kagamimori S, Nakagawa H, Oyabe S. High-density lipoprotein cholesterol and risk of stroke in Japanese men and women: the Oyabe Study. Stroke. 2003;34:863-8.

6. Heller DA, de Faire U, Pedersen NL, Dahlen G, McClearn GE. Genetic and environmental influences on serum lipid levels in twins. N Engl J Med. 1993;328:1150-6.

7. Marenberg ME, Risch N, Berkman LF, Floderus B, de Faire U. Genetic susceptibility to death from coronary heart disease in a study of twins. N Engl J Med. 1994;330:1041-6.

8. Keavney B, Palmer A, Parish S, Clark S, Youngman L, Danesh J, McKenzie C, Delepine M, Lathrop M, Peto R, et al. Lipid-related genes and myocardial infarction in 4685 cases and 3460 controls: discrepancies between genotype, blood lipid concentrations, and coronary disease risk. Int J Epidemiol. 2004;33:1002-13.

9. Health Quality O. Cancer screening with digital mammography for women at average risk for breast cancer, magnetic resonance imaging (MRI) for women at high risk: an evidence-based analysis. Ont Health Technol Assess Ser. 2010;10:1-55.

10. Ramadan S, Arm J, Silcock J, Santamaria G, Buck J, Roy M, Leong KM, Lau P, Clark D, Malycha P, Mountford C. Lipid and Metabolite Deregulation in the Breast Tissue of Women Carrying BRCA1 and BRCA2 Genetic Mutations. Radiology. 2015;275:675-82.

11. Jeemon P, Pettigrew K, Sainsbury C, Prabhakaran D, Padmanabhan S. Implications of discoveries from genome-wide association studies in current cardiovascular practice. World J Cardiol. 2011;3:230-47.

12. Asselbergs FW, Guo Y, van Iperen EP, Sivapalaratnam S, Tragante V, Lanktree MB, Lange LA, Almoguera B, Appelman YE, Barnard J, et al. Large-scale gene-centric meta-analysis across 32 studies identifies multiple lipid loci. Am J Hum Genet. 2012;91:823-38.

13. Teslovich TM, Musunuru K, Smith AV, Edmondson AC, Stylianou IM, Koseki M, Pirruccello JP, Ripatti S, Chasman DI, Willer CJ, et al. Biological, clinical and population relevance of 95 loci for blood lipids. Nature. 2010;466:707-13.

14. Miao L, Yin RX, Yang S, Pan SL, Lin WX, Yang DZ. BRCA2 rs 9534275 polymorphism and serum lipid traits in the Maonan and Han populations. Int J Clin Exp Pathol. 2017;10:3163-78.

15. Zhou YJ, Hong SC, Yin RX, Yang Q, Cao XL, Chen WX. Polymorphisms in the GCKR are associated with serum lipid traits, the risk of coronary artery disease and ischemic stroke. Int J Clin Exp Med. 2015;8:10678-86.

16. Wu DF, Yin RX, Cao XL, Chen WX, Aung LH, Wang W, Huang KK, Huang P, Zeng XN, Wu J. Scavenger receptor class B type 1 gene rs5888 single nucleotide polymorphism and the risk of coronary artery disease and ischemic stroke: a case-control study. Int J Med Sci. 2013;10:1771-7.

17. Wu DF, Yin RX, Cao XL, Chen WX. Association between single nucleotide polymorphism rs1044925 and the risk of coronary artery disease and ischemic stroke. Int J Mol Sci. 2014;15:3546-59.

18. Grov C, Wells BE, Parsons JT. Self-reported penis size and experiences with condoms among gay and bisexual men. Arch Sex Behav. 2013;42:313-22.

19. Wu DF, Yin RX, Aung LH, Li Q, Yan TT, Zeng XN, Huang KK, Huang $P$, JZ W, Pan SL. Sex-specific association of ACAT-1 rs1044925 SNP and serum lipid levels in the hypercholesterolemic subjects. Lipids Health Dis. 2012;11:9.

20. Wu DF, Yin RX, Aung LH, XJ H, Cao XL, Miao L, Li Q, Yan TT, JZ W, Pan SL. Polymorphism of rs1044925 in the acyl-CoA:cholesterol acyltransferase-1. gene and serum lipid levels in the Guangxi Bai Ku Yao and Han populations. Lipids Health Dis. 2010;9:139.

21. Chalmers J, MacMahon S, Mancia G, Whitworth J, Beilin L, Hansson L, Neal B, Rodgers A, Ni Mhurchu C, Clark T. World Health Organization-International Society of Hypertension Guidelines for the management of hypertension. Guidelines sub-committee of the World Health Organization. Clin Exp Hypertens. 1999;1999(21):1009-60.

22. Zhou BF, Cooperative Meta-Analysis Group of the Working Group on Obesity in C. Predictive values of body mass index and waist circumference for risk factors of certain related diseases in Chinese adults-study on optimal cut-off points of body mass index and waist circumference in Chinese adults. Biomed Environ Sci. 2002;15:83-96.

23. Alberti KG, Zimmet PZ. Definition, diagnosis and classification of diabetes mellitus and its complications. Part 1: diagnosis and classification of diabetes mellitus provisional report of a WHO consultation. Diabet Med. 1998;15:539-53.

24. Peden JF, Farrall M. Thirty-five common variants for coronary artery disease: the fruits of much collaborative labour. Hum Mol Genet. 2011:20:R198-205.

25. van den Hoogen PC, Feskens EJ, Nagelkerke NJ, Menotti A, Nissinen A, Kromhout $\mathrm{D}$. The relation between blood pressure and mortality due to coronary heart disease among men in different parts of the world. Seven Countries Study Research Group. N Engl J Med. 2000;342:1-8.

26. Global Burden of Metabolic Risk Factors for Chronic Diseases C, Lu Y, Hajifathalian K, Ezzati M, Woodward M, Rimm EB, Danaei G. Metabolic mediators of the effects of body-mass index, overweight, and obesity on coronary heart disease and stroke: a pooled analysis of 97 prospective cohorts with 1.8 million participants. Lancet. 2014;383:970-83.

27. Romero-Corral A, Montori VM, Somers VK, Korinek J, Thomas RJ, Allison TG, Mookadam F, Lopez-Jimenez F. Association of bodyweight with total mortality and with cardiovascular events in coronary artery disease: a systematic review of cohort studies. Lancet. 2006;368:666-78.

28. Group AS, Cushman WC, Evans GW, Byington RP, Goff DC, Jr., Grimm RH, Jr., Cutler JA, Simons-Morton DG, Basile JN, Corson MA, et al: Effects of intensive blood-pressure control in type 2 diabetes mellitus. N Engl J Med 2010, 362:1575-1585.

29. Libby P, Theroux P. Pathophysiology of coronary artery disease. Circulation. 2005;111:3481-8.

30. Eckel RH, Grundy SM, Zimmet PZ. The metabolic syndrome. Lancet. 2005;365:1415-28

31. Messerli FH, Williams B, Ritz E. Essential hypertension. Lancet. 2007;370:591-603.

32. Lagrand WK, Visser CA, Hermens WT, Niessen HW, Verheugt FW, Wolbink GJ, Hack CE. C-reactive protein as a cardiovascular risk factor: more than an epiphenomenon? Circulation. 1999;100:96-102.

33. Moran O, Nikitina D, Royer R, Poll A, Metcalfe K, Narod SA, Akbari MR, Kotsopoulos J. Revisiting breast cancer patients who previously tested negative for BRCA mutations using a 12-gene panel. Breast Cancer Res Treat. 2017;161:135-42. 
34. Hsu PP, Sabatini DM. Cancer cell metabolism: Warburg and beyond. Cell. 2008;134:703-7.

35. Nelson ER, Wardell SE, Jasper JS, Park S, Suchindran S, Howe MK, Carver NJ, Pillai RV, Sullivan PM, Sondhi V, et al. 27-Hydroxycholesterol links hypercholesterolemia and breast cancer pathophysiology. Science. 2013;342:1094-8.

36. Pasternak RC, Criqui MH, Benjamin EJ, Fowkes FG, Isselbacher EM, McCullough PA, Wolf PA, Zheng ZJ, American Heart A. Atherosclerotic Vascular Disease Conference: Writing Group I: epidemiology. Circulation. 2004;109:2605-12.

37. Bangalore S, Fayyad R, Laskey R, DeMicco DA, Messerli FH, Waters DD. BodyWeight Fluctuations and Outcomes in Coronary Disease. N Engl J Med. 2017;376:1332-40

38. Aune D, Sen A, Norat T, Janszky I, Romundstad P, Tonstad S, Vatten L. Body Mass Index, Abdominal Fatness, and Heart Failure Incidence and Mortality: A Systematic Review and Dose-Response Meta-Analysis of Prospective Studies. Circulation. 2016;133:639-49.

39. Pandey A, Berry JD, Lavie CJ. Cardiometabolic Disease Leading to Heart Failure: Better Fat and Fit Than Lean and Lazy. Curr Heart Fail Rep. 2015;12:302-8.

40. Zalesin KC, Franklin BA, Miller WM, Peterson ED, McCullough PA. Impact of obesity on cardiovascular disease. Med Clin North Am. 2011;95:919-37.

41. Poirier P, Giles TD, Bray GA, Hong Y, Stern JS, Pi-Sunyer FX, Eckel RH, American Heart A. Obesity Committee of the Council on Nutrition PA Metabolism: Obesity and cardiovascular disease: pathophysiology, evaluation, and effect of weight loss: an update of the 1997 American Heart Association Scientific Statement on Obesity and Heart Disease from the Obesity Committee of the Council on Nutrition, Physical Activity, and Metabolism. Circulation. 2006;113:898-918.

42. Maeda K, Noguchi Y, Fukui T. The effects of cessation from cigarette smoking on the lipid and lipoprotein profiles: a meta-analysis. Prev Med. 2003:37:283-90.

43. Xu T, Holzapfel C, Dong X, Bader E, Yu Z, Prehn C, Perstorfer K, Jaremek M, Roemisch-Margl W, Rathmann W, et al. Effects of smoking and smoking cessation on human serum metabolite profile: results from the KORA cohort study. BMC Med. 2013;11:60.

44. Takata K, Imaizumi S, Kawachi E, Suematsu Y, Shimizu T, Abe S, Matsuo Y, Tsukahara H, Noda K, Yahiro E, et al. Impact of cigarette smoking cessation on high-density lipoprotein functionality. Circ J. 2014:78:2955-62

45. Wenger NK, Shaw $\sqcup$, Vaccarino V. Coronary heart disease in women: update 2008. Clin Pharmacol Ther. 2008:83:37-51.

\section{Submit your next manuscript to BioMed Central and we will help you at every step:}

- We accept pre-submission inquiries

- Our selector tool helps you to find the most relevant journal

- We provide round the clock customer support

- Convenient online submission

- Thorough peer review

- Inclusion in PubMed and all major indexing services

- Maximum visibility for your research

Submit your manuscript at www biomedcentral.com/submit

) Biomed Central 